\title{
A New Glycoside of Resveratrol Dimer from Stem Bark of Vitis vinifera
}

\author{
Chun Whan Choi, ${ }^{\dagger,}$ Yeon Hee Choi, ${ }^{\dagger}$ Mi-Ran Cha, ${ }^{\dagger \neq}$ Dae Seok Yoo, ${ }^{\dagger \neq}$ Young Sup Kim, ${ }^{\dagger}$ Gyu hwan Yon, ${ }^{\dagger}$ \\ Sang Un Choi, ${ }^{\dagger}$ Young Ho Kim, ${ }^{\ddagger}, *$ and Shi Yong Ryu ${ }^{\dagger \dagger}$ *
}

${ }^{\dagger}$ Korea Research Institute of Chemical Technology, Daejeon 305-606, Korea. *E-mail: syryu@krict.re.kr ${ }^{\ddagger}$ College of Pharmacy Chungnam National University, Daejeon 305-764, Korea. *E-mail: yhk@cnu.ac.kr Received August 16, 2010, Accepted September 15, 2010

Key Words: Vitis vinifera, Antitumor, Resveratrol dimer

Vitis vinifera (common grapevine) is a perennial and deciduous woody vine of the genus Vitis, native to the Mediterranean region, central Europe, and southwestern Asia and commonly cultivated on every Continent on Earth nowadays. Lots of health benefits of grapevine such as chemopreventive, antimicrobial, antioxidant and anti-inflammatory activities ${ }^{1-4}$ has been reported and resveratrol (3,5,4'-trihydroxystilbene), a reputed constituent of grapevine is regarded as an active principle of above mentioned biological activities. Grapevine is known as an important source of resveratrol and many naturally occurring hydroxystilbene components. ${ }^{5}$

In the course of examining the inhibitory effect of various kinds of plant extracts on the proliferation of tumor cells, we have found that a methanol extract from stem bark of grapevine exhibited a potent inhibition on the proliferation of cultured human tumor cells such as A549 (non small cell), SK-OV-3
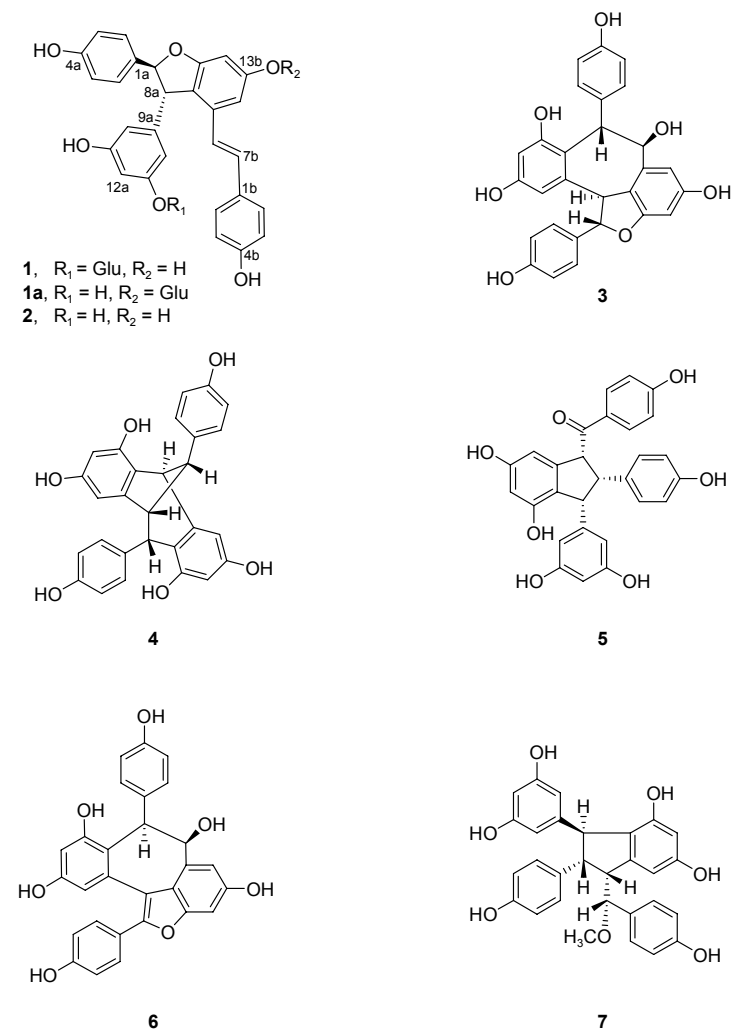

(ovary) and SK-MEL-2 (melanoma) in a dose dependent manner, in vitro.

Thus, a bioassay-guided fractionation of the extract had performed and finally led to the isolation of a new glycoside of resveratrol dimer, (-)- $\varepsilon$-viniferin glycoside (1) and nine related resveratrol oligomers, i.e., $\varepsilon$-viniferin (2), ${ }^{6}$ ampelopsin A (3), ${ }^{7}$ isoampelopsin F (4), ${ }^{8}$ caraphenol B (5), ${ }^{8}$ malibatol A (6), ${ }^{9}$ viniferaether B (7), ${ }^{10}$ vitisin A (8), ${ }^{6}$ cis-vitisin A (9), ${ }^{11}$ vitisin $\mathrm{B}(\mathbf{1 0})^{6}$ as active ingredients responsible for the antitumoral property. Structures of the isolated active components (1-10) were established by chemical and spectroscopic means. In the present paper, we describe the identification of a new glycoside of resveratrol dimer (1), together with the cytotoxic effect of ten resveratrol oligomers (1-10) isolated from the stem bark extract of grapevine (Fig. 1).

Compound 1, an amorphous yellow powder, $[\alpha]_{\mathrm{D}}^{20}:-15.0$
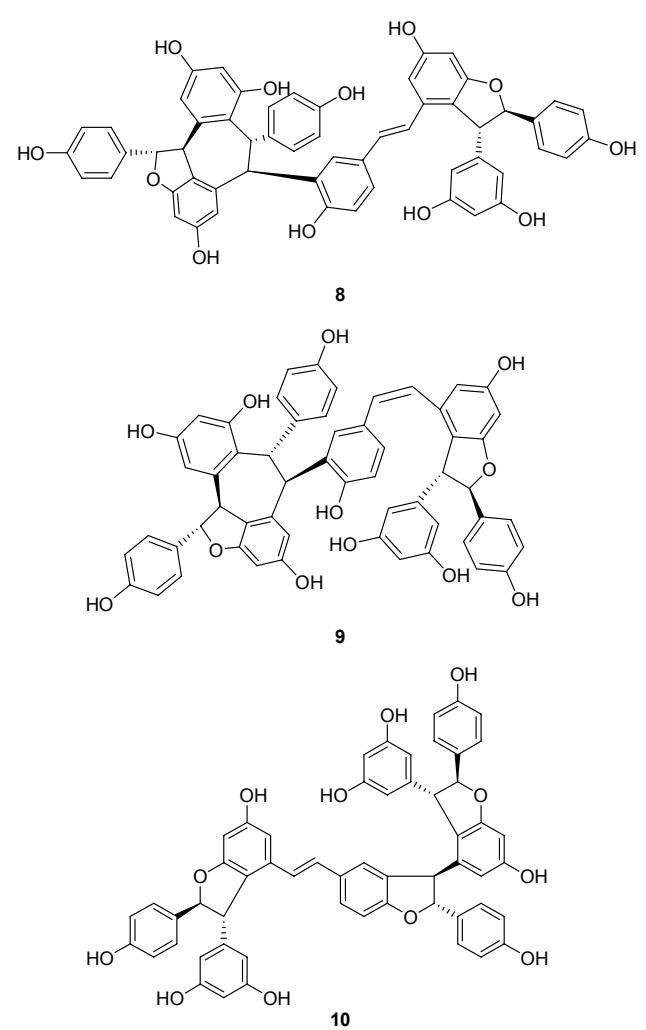

Figure 1. Structures of isolated resveratrol and its derivatives isolated from stem bark extracts of Vitis vinifera. 


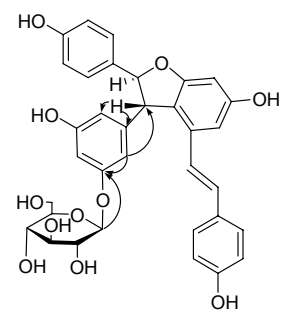

Figure 2. Important HMBC correlations for 1.

Table 1. ${ }^{1} \mathrm{H}$ - and ${ }^{13} \mathrm{C}-\mathrm{NMR}$ spectral data for compounds $\mathbf{1}^{a}$ and $\mathbf{1 a}$

\begin{tabular}{|c|c|c|c|c|}
\hline & ${ }^{1} \mathrm{H}(\mathbf{1})$ & ${ }^{1} \mathrm{H}(\mathbf{1} \mathbf{a})^{b}$ & ${ }^{13} \mathrm{C}(\mathbf{1})$ & ${ }^{13} \mathrm{C}(\mathbf{1 a})$ \\
\hline $1 \mathrm{a}$ & & & 133.8 & 133.7 \\
\hline $2 a, 6 \mathbf{a}$ & $7.22(\mathrm{~d}, 8.4)$ & $7.20(\mathrm{~d}, 8.5)$ & 128.0 & 128.0 \\
\hline $3 a, 5 a$ & $6.85(\mathrm{~d}, 8.4)$ & $6.83(\mathrm{~d}, 8.5)$ & 116.2 & 116.2 \\
\hline $4 a$ & & & 158.2 & 158.3 \\
\hline $7 \mathbf{a}$ & $5.49(\mathrm{~d}, 5.4)$ & $5.45(\mathrm{~d}, 5.4)$ & 94.0 & 94.0 \\
\hline $\mathbf{8 a}$ & $4.56(\mathrm{~d}, 5.4)$ & $4.51(\mathrm{~d}, 5.4)$ & 57.0 & 57.0 \\
\hline 9a & & & 147.4 & 147.1 \\
\hline $10 a$ & 6.43 , br s & $6.23(\mathrm{~s})$ & 109.3 & 107.0 \\
\hline $11 \mathrm{a}$ & & & 159.6 & 159.9 \\
\hline $12 a$ & 6.52 , br s & $6.23(\mathrm{~s})$ & 103.0 & 102.2 \\
\hline $13 a$ & & & 160.4 & 159.9 \\
\hline $14 a$ & 6.46 , br s & $6.23(\mathrm{~s})$ & 108.6 & 107.0 \\
\hline 1b & & & 129.8 & 129.9 \\
\hline $2 b, 6 b$ & $7.19(\mathrm{~d}, 8.7)$ & $7.18(\mathrm{~d}, 8.7)$ & 128.8 & 128.8 \\
\hline $3 b, 5 b$ & $6.77(\mathrm{~d}, 8.7)$ & $6.73(\mathrm{~d}, 8.7)$ & 116.4 & 116.3 \\
\hline $4 b$ & & & 158.2 & 158.3 \\
\hline $7 b$ & $6.93(\mathrm{~d}, 16.2)$ & $7.01(\mathrm{~d}, 15.8)$ & 130.3 & 130.7 \\
\hline $8 b$ & $6.70(\mathrm{~d}, 16.2)$ & $6.71(\mathrm{~d}, 15.8)$ & 123.2 & 123.2 \\
\hline $9 b$ & & & 136.4 & 136.4 \\
\hline $10 \mathrm{~b}$ & & & 119.6 & 122.3 \\
\hline $11 b$ & & & 162.5 & 162.1 \\
\hline $12 b$ & $6.36(\mathrm{~d}, 1.8)$ & $6.53(\mathrm{~d}, 2.0)$ & 96.9 & 98.0 \\
\hline $13 b$ & & & 159.7 & 160.4 \\
\hline $14 b$ & $6.76(\mathrm{~d}, 1.8)$ & $7.01(\mathrm{~d}, 2.0)$ & 104.3 & 105.5 \\
\hline $\mathbf{1}^{\prime}$ & $4.74(\mathrm{~d}, 7.6)$ & $4.99(\mathrm{~d}, 7.3)$ & 102.1 & 102.5 \\
\hline $2^{\prime}$ & $3.47, \mathrm{~m}$ & $3.47, \mathrm{~m}$ & 74.6 & 74.8 \\
\hline $3^{\prime}$ & $3.51, \mathrm{~m}$ & $3.45, \mathrm{~m}$ & 71.1 & 71.5 \\
\hline $4^{\prime}$ & $3.47, \mathrm{~m}$ & $3.57, \mathrm{~m}$ & 77.5 & 78.0 \\
\hline $5^{\prime}$ & $3.56, \mathrm{~m}$ & $3.53, \mathrm{~m}$ & 77.8 & 78.4 \\
\hline $6^{\prime}$ & $3.73, \mathrm{~m}$ & $3.95, \mathrm{~m}$ & 62.4 & 62.8 \\
\hline
\end{tabular}

1 and $1 \mathrm{a}$ were measured in $\mathrm{CD}_{3} \mathrm{COCD}_{3} .300 \mathrm{MHz}\left({ }^{1} \mathrm{H}\right)$ and $75 \mathrm{MHz}\left({ }^{13} \mathrm{C}\right)$. ${ }^{a}$ TMS was used as the internal standard; chemical shifts are shown in the $\delta$ scale with $J$ values in parenthesis. br s: broad singlet; d: doublet; m: multiple.

(C $\left.0.1, \mathrm{CH}_{3} \mathrm{OH}\right)$. The HRESIMS exhibited a molecular ion peak at $m / z 639.1838[\mathrm{M}+\mathrm{Na}]^{+}$, consistent with a molecular formula of $\mathrm{C}_{34} \mathrm{H}_{32} \mathrm{O}_{11}$. The ${ }^{1} \mathrm{H}$ and ${ }^{13} \mathrm{C}$ signals of $\mathbf{1}$ in the aromatic region were almost superimposable with those of $\varepsilon$-viniferin $(\mathbf{2}){ }^{6}$ a well known resveratrol dimer found in grapevines. The molecular formula and additional six carbon signals (five oxygenated methines and one methylene) of $\mathbf{1}$ compared with those of $\mathbf{2}$ strongly implied that $\mathbf{1}$ was a monoglycosidic congener of $\mathbf{2}$. All
Table 2. Inhibition of tumor cell proliferation by resveratrol and its derivatives isolated from stem bark extracts of Vitis vinifera

\begin{tabular}{crcc}
\hline \multirow{3}{*}{ Compound } & \multicolumn{3}{c}{$\mathrm{ED}_{50}(\mu \mathrm{M})^{a}$} \\
\cline { 2 - 4 } & \multicolumn{1}{c}{ A549 } & SK-OV-3 & SK-MEL-2 \\
\hline $\mathbf{2}$ & $18.64 \pm 2.24$ & $13.91 \pm 1.17$ & $13.75 \pm 3.14$ \\
$\mathbf{3}$ & $26.41 \pm 2.17$ & $14.80 \pm 0.30$ & $>30.0$ \\
$\mathbf{8}$ & $3.49 \pm 0.14$ & $1.71 \pm 0.31$ & $33.28 \pm 3.14$ \\
$\mathbf{9}$ & $0.93 \pm 0.21$ & $0.17 \pm 0.06$ & $13.04 \pm 1.34$ \\
$\mathbf{1 0}$ & $18.63 \pm 2.31$ & $4.11 \pm 0.12$ & $4.85 \pm 0.94$ \\
Etoposide & $2.61 \pm 0.13$ & $2.90 \pm 0.37$ & $2.73 \pm 0.29$
\end{tabular}

${ }^{a} \mathrm{ED}_{50}$ value of compound against each cancer cell line, which was defined as a concentration $(\mu \mathrm{M})$ that caused $50 \%$ inhibition of cell proliferation in vitro. Data are expressed as mean $\pm \mathrm{SEM}$ of three separate experiments.

proton signals and carbon signals of 1 were completely assigned by the aid of two-dimensional NMR experiments, COSY, DEPT, HMQC and HMBC. The enzymatic hydrolysis of 1 with hesperidinase gave a D-glucose and $\mathbf{2}$, respectively. D-glucose determined by TLC over silica gel $\left(\mathrm{CH}_{2} \mathrm{Cl}_{2}-\mathrm{MeOH}-\mathrm{H}_{2} \mathrm{O}=8: 5: 1\right)$ by comparison with authentic samples. The linkage pattern of $\mathrm{D}$-glucose was established as $\beta$-orientation by the coupling constant $(J=7.6 \mathrm{~Hz})$ of anomeric proton $\left(\mathrm{H}-1^{\prime}\right)$ and the attached point of glycosidic linkage was confirmed by HMBC spectral data (Fig. 2), i.e., the anomeric proton (H-1') showed a correlations with $\mathrm{C}-11 \mathrm{a}$, which suggested that a D-glucose was linked at the hydroxyl group of C-11a of 2 via $\beta$-glycosidic linkage as depicted in Fig. 1. A monoglycosidic compound 2, paucifloroside A (1a) has been recently isolated from the stem bark of Vatica pauciflora. ${ }^{12}$ However, 1a had a different glycosidic linkage point (C-13b) as depicted in Fig. 1. All proton signals and carbon signals of $\mathbf{1}$ were observed to be slightly different with those of $1 \mathrm{a}$, which were summarized in Table 1. And absolute stereochemistry of C-7a and C-8a determined using $\mathrm{CD}$ spectroscopic evidence. ${ }^{14}$ In circular dichroism (CD) experiments, compound 1 showed a positive cotton effect near $236 \mathrm{~nm}$. To the best of our knowledge, 1 has never been isolated before neither from grapevines nor from any other natural resources.

All isolated resveratrol oligomers (1-10) were evaluated for the inhibitory activity on the proliferation of cultured human tumor cell lines such as A549 (non small cell lung), SK-OV-3 (ovary) and SK-MEL-2 (melanoma) by SRB method, in vitro. The concentration of compounds required for $50 \%$ proliferation of tested tumor cells (ED ( $_{50}$ ) were summarized in Table 2. However, 1 and 4-8 did not exhibit a significant inhibition on the proliferation of tested tumor cells below $30 \mu \mathrm{M}$, respectively. Moreover, Anti-proliferative activity of resveratrol dimers (1-7) were much less potent than those of resveratrol tetramers $(\mathbf{8 - 1 0})$ on each tested tumor cells.

\section{Experimental Section}

General procedures. The High resolution electrospray ionization (HRESI) and electron impact (EI) mass spectra were obtained using a Q-Tof micro LC-MS/MS instrument (Waters, USA) and CP3800-1200L (Varian, USA) mass spectrometer, respectively. ${ }^{1} \mathrm{H}-\mathrm{NMR}$ (nuclear magnetic resonance), and ${ }^{13} \mathrm{C}$ - 
NMR spectra were recorded on a Bruker (Rheinstetten, Germany) AM 300, AMX 500 and AMX 800 NMR spectrometer using TMS as an internal standard. Column chromatography was performed using a silica gel (Kieselgel 60, 70 - 230 mesh, Merck, Darmstadt, Germany), and Lichroprep RP-18 (40 - 63 $\mathrm{mm}$, Merck). Thin layer chromatography (TLC) analysis was performed on Kieselgel 60 F254 plates (silica gel, $0.25 \mathrm{~mm}$, Merck)and spots were detected under a UV lamp Spectroline Medel ENF-240 C/F (Spectronics Corporation, Westbury, NY) followed by $10 \% \mathrm{H}_{2} \mathrm{SO}_{4}$ reagent. Solvents and reagents were obtained from commercial sources and used without further purification. Hesperidinase was a purchased from Tokyo Tanabe Pharmaceutical Co., Ltd. (Tokyo, Japan).

Plant material. The stem bark of Vitis vinifera were harvested in October 2008 from the vineyard, Yuseong, Korea. A voucher specimen (KR0331) was deposited at the herbarium of the Korea Research Institute of Chemical Technology.

Extraction and isolation. The stem bark of Vitis vinifera $(10$ $\mathrm{kg}$ ) were extracted twice with $50 \mathrm{~L}$ of ethanol (EtOH) by maceration at room temperature for 7 days. After filtration with cotton ball, the filtrate was combined and evaporated to dryness to give $708.8 \mathrm{~g}$ of dark syrupy extract. The ethanol extract was suspended in $20 \mathrm{~L}$ of water and partitioned sequentially with equal volume of $\mathrm{CH}_{2} \mathrm{Cl}_{2}$, EtOAc and $n-\mathrm{BuOH}$. The EtOAc soluble fraction $(463.8 \mathrm{~g})$ was subjected to silica gel $(5.0 \mathrm{~kg})$ column $(15 \times 60 \mathrm{~cm})$ chromatography, eluted with $\mathrm{MeOH}$ in $\mathrm{CH}_{2} \mathrm{Cl}_{2}$ in a step-gradient manner from $1 \%$ to $50 \%$ to give six fractions (F1: 32.9 g, F2: 39.8 g, F3: 28.1 g, F4: 195.8 g, F5: $39.2 \mathrm{~g}$ and F6: $110.2 \mathrm{~g})$. The fraction F2 was further purified by ODS $(500 \mathrm{~g})$ column $(2.0 \times 40 \mathrm{~cm})$ chromatography, which produced 230 $\mathrm{mg}$ of 2 . Fraction F3 was further purified by silica gel column chromatography in a similar manner to that described above and eluted with $\mathrm{MeOH}$ in $\mathrm{CH}_{2} \mathrm{Cl}_{2}$ in a step-gradient manner, from $1 \%$ to $50 \%$ to produce six fractions (F31-F38). F34 was also purified by a similar manner with RP- 18 column chromatography eluted with $\mathrm{MeOH}$ in $\mathrm{H}_{2} \mathrm{O}(1 \%$ to $100 \%)$ in a stepwise gradient, which finally gave $15 \mathrm{mg}$ of compound 3 and $48 \mathrm{mg}$ of 7, respectively. Fifteen $\mathrm{mg}$ of $\mathbf{4}$ was obtained by crystallization of F343 in $\mathrm{MeOH}$. After removal of 4, the remained mother liquor of F343 was further purified by RP-18 column chromatography eluted with $\mathrm{MeOH}$ in $\mathrm{H}_{2} \mathrm{O}(1 \%$ to $100 \%)$ in a stepwise gradient, which finally gave $9 \mathrm{mg}$ of 6 and $3 \mathrm{mg}$ of 5 . Repeated RP-18 chromatography of F4 and F5 with step-gradient elution of $\mathrm{MeOH}$ in $\mathrm{H}_{2} \mathrm{O}$ finally resulted in the purification of $9.1 \mathrm{~g}$ of $\mathbf{1 0}$ and $90 \mathrm{mg}$ of $\mathbf{1}$ from F4, and $8.1 \mathrm{~g}$ of $\mathbf{8}$ and 210 $\mathrm{mg} 9$ from F5.

(-)- $\varepsilon$-Viniferin glycoside (1): Amorphous yellow powder; $[\alpha]_{\mathrm{D}}^{20}:-15.0\left(C 0.1, \mathrm{CH}_{3} \mathrm{OH}\right) .{ }^{1} \mathrm{H}$ and ${ }^{13} \mathrm{C}-\mathrm{NMR}$ spectra data: Table 1; HRESIMS: $m / z 639.1838[\mathrm{M}+\mathrm{Na}]^{+}$, calcd for $\mathrm{C}_{34} \mathrm{H}_{32}$ $\mathrm{O}_{11} \mathrm{Na}, 639.1842$.

In vitro cytotoxicity assays. All of the experimental procedures followed the NCI's protocols with some minor changes based on the sulforhodamine B (SRB) method as described previously. ${ }^{15}$

Acknowledgments. This study was supported in part by funds from Ministry of Knowledge Economy, Korea and also by the support of 'Forest Science \& Technology Projects (Project No. S120808L1101104)' provided by Korea Forest Service.

\section{Reference}

1. Iliya, I.; Ali, Z.; Tanaka, T.; Iinuma, M.; Furusawa, M.; Nakaya, K.; Murata, J.; Darnaedi, D.; Matsuura, N.; Ubukata, M. Phytochemistry 2003, 62, 601.

2. Pryce, R. J.; Langcake, P. Phytochemistry 1977, 16, 1452.

3. Bokel, M.; Champikadiyasena, M. N.; Lesliegunatilaka, A. A.; Kraus, W.; Sotheeswaran, S. Phytochemistry 1988, 27, 377.

4. Kitanaka, S.; Ikezawa, T.; Yasukawa, K.; Yamanouchi, S.; Takido, M.; Sung, H. K.; Kim, J. H. Chem. Pharm. Bull. 1990, 38, 432.

5. Yan, K. X.; Terashima, K.; Takaya, Y.; Niwa, M. Tetrahedron 2001, 57, 2711

6. Ito, J.; Takaya, Y.; Oshima, Y.; Niwa, M. Tetrahedron 1999, 55, 2529.

7. Ha, D. T.; Chen, Q. C.; Hung, T. M.; Youn, U. J.; Ngoc, T. M.; Thuong, P. T.; Kim, H. J.; Seong, Y. H.; Min, B. S.; Bae, K. Arch. Pharm. Res. 2009, 32, 177.

8. Luo, H. F.; Zhang, L. P.; Hu, C. Q. Tetrahedron 2001, 57, 4849.

9. Dai, J. R.; Hallock, Y. F.; Cardellina, J. H., II.; Boyd, M. R. J. Nat. Prod. 1998, 61, 351.

10. Fuji, F.; He, Y. H.; Terashima, K.; Takaya, J.; Niwa, M. Heterocycles 2005, 65, 2461.

11. Ito, J.; Gobaru, K.; Shimamura, T.; Niwa, M.; Takaya, Y.; Oshima, Y. Tetrahedron 1998, 54, 6651.

12. Ito, T.; Tanaka, T.; Iinuma, M.; Iliya, I.; Nakaya, K. I.; Ali, Z.; Takahashi, Y.; Sawa, R.; Shirataki, Y.; Murata, J.; Darnaedi, D. Tetrahedron 2003, 59, 5347.

13. Agrawal, P. K. Phytochemistry 1992, 31, 3307.

14. Ito, T.; Abe, N.; Oyama, M.; Iinuma, M. Tetrahedron Lett. 2009, $50,2516$.

15. Ryu, S. Y.; Choi, S. U.; Lee, C. O.; Zee, O. P. Arch. Pharm. Res. 1992, 15,356 . 